\title{
A retrospective study on status of CD4 counts and effect of ART in patients attending VCTC of MGM Hospital, Warangal, Andhra Pradesh, India
}

\author{
K. Suresh Babu ${ }^{1}$, Ch. Ram Babu ${ }^{2}$, N. Baratha Jyothi ${ }^{3}$ and K. Sunita ${ }^{4 *}$ \\ ${ }^{1,2,3,4}$ Department of Zoology and Aquaculture, Acharya Nagarjuna University, \\ Nagarjunanagar 522 510, Guntur, Andhra Pradesh, India.
}

\begin{abstract}
The present article deals with the status of CD4 count and effect of antiretroviral treatment (ART) in clients attending the ART and VCTC at Warangal district, Andhra Pradesh. It is a retrospective cross-sectional record-based study for two years of follow-up. According to the present study, 139 subjects have taken ART aged up to 50 years. Out of 139 patients, 106 (76.3\%) were males; while 33 (23.7\%) were females. It has shown that, there is a significant change $(t=2.18, p<0.05)$ between the baseline CD4 count of male and female subjects. Majority of the patients in our study had shown CD4 count ranging between $101-200$ cells/cmm and the mean rise in CD4 count is 325.4 cells/cmm after 6 months of ART. So, a significant increase was observed in CD4 count $(p<0.05)$ from baseline to follow up in the study patients. Thus, a significant relationship was established between the ART and the increase in CD4 count $(t=18.84, p<0.001)$. The study patients taking Nevirapine containing regimens has shown significant increase in the CD4 levels just after 6 months of followup. Hence, antiretroviral therapy in the study patients increased the levels of CD4 counts gradually from baseline to follow up after 6 months of ART.
\end{abstract}

Keywords: CD4 count, ART, HIV+ve subjects, ARVs

\section{Introduction}

More people than ever are living with HIV, largely due to greater access to treatment. At the end of 2010, an estimated 34 million people [31.6 million-35.2 million] were living with HIV worldwide, up 17\% from 2001. This reflects the continued large number of new HIV infections and a significant expansion of access to antiretroviral therapy (ART), which has helped reduce AIDS (Acquired Immunodeficiency Syndrome) - related deaths, especially in more recent years [1].

Andhra Pradesh has been identified as one of the six high HIV- prevalence states of India. It accounts for an estimated 10 percent of the HIV cases in India. According to the UNAIDS estimates for the year 2004, of the 42 million people living with HIV and AIDS (PLWHA) in the world, around five million are in India, and of these almost one tenth, i.e., around five hundred thousand are in Andhra Pradesh. Of the total number of $1,11,608$ AIDS cases reported in the country till 2005, as many as 12,349 cases, accounting for nearly 11.06 percent are from Andhra Pradesh. So far, the state has recorded 739 AIDS related deaths.

India alone accounts for more than $10 \%$ global HIV/AIDS cases and is currently living with approximately 2.5 million HIV/AIDS positive victims and many more lakhs with STIs. Current situation that the HIV epidemic has moved beyond high risk populations like sex workers, truckers and MSM has become a generalized epidemic with a staggering $92 \%$ of infections being in the age group of 15-49 years, which is also the most economically productive segment of the population [1].

The ANC prevalence was higher in Andhra Pradesh than in any other state. A vast majority of infections in Andhra Pradesh are believed to result from sexual transmission. The sentinel surveillance in various districts of the state, reports HIV prevalence is around 23\% among samples from STD clinic attendees (potentially high risk population) and around $1.6 \%$ among the antenatal care (ANC) clinic attendees (potentially representing the currently low risk general population). Of the 23 districts in the state, 17 districts have reported generalized HIV epidemic. Of these, around $91 \%$ of the HIV transmission occurs through sexual mode. Prevalence is more amongst high risk groups like STD attendees 17.2\%, MSM $17.04 \%$, FSW 9.74\% and IDU $3.71 \%$. Males who engage in high risk behavior are said to act as a "bridge" population who may transmit HIV to people without identified risk behavior such as their wives [2].

We are on the verge of a significant breakthrough in the AIDS response living with and affected by HIV. The vision of a world with zero new HIV infections, zero discrimination, and zero AIDS-related deaths has captured the imagination of diverse partners, stake holders and people living with and affected by HIV. New HIV infections continue to fall and more people than ever are starting treatment. With research giving us solid evidence that antiretroviral therapy can prevent new HIV infections, it is encouraging that 6.6 million people are now receiving treatment in low- and middle-income countries: nearly half those eligible [1]. Hence, the present 
A retrospective study on status of CD4 counts and effect of ART in patients attending VCTC of .....

study is made to understand clearly about the effect of ART and the status of CD4 counts in study patients. This gives the insight into the need and urgency of antiretroviral therapy to HIV/AIDS infected people.

\subsection{Study Area:}

\section{Materials and methods}

The present study was conducted in Warangal district, Andhra Pradesh state, India. Warangal is located at $18.0^{\circ} \mathrm{N}$ latitude and $79.58^{\circ} \mathrm{E}$ longitude. It has an average elevation of 302 meters (990 feet). The present study was carried out at MGM Hospital, Warangal. As of 2011 India Census, Warangal had a population of $35,22,644$ of which male and female were 17,66,257 and 17,56,387 respectively. Warangal district population constitutes $4.16 \%$ of total Maharashtra population. Average literacy rate of Warangal in 2011 were 66.16 compared to 57.13 of 2001. If things are looked out at gender wise, male and female literacy were 75.91 and 56.45 respectively. In Warangal $9.21 \%$ of the population is less than 6 years of age.

\subsection{Sample size:}

To study the effect of antiretroviral therapy, a total of 139 HIV positive patients were recruited and were medicated at ART centre twice (initially the HIV patients were tested for baseline CD4 counts and those who showed $<300$ cells/cmm were given ART and follow-up visit with at least 6 months gap. The given data regarding HIV infected people was collected from the VCTC and ART Centre, MGM Hospital, Warangal.

\subsection{Dual Platform Cytometry:}

NACO as per WHO strategy - II, 1993. After confirmation of HIV infection by VCTC center in the Department of Microbiology of the Institute, CD4 count was calculated. CD4 lymphocyte counts were determined by FACS Calibur Flow Cytometry (Becton Dickinson). Specific opportunistic infections were diagnosed on the basis of standard clinical definitions and laboratory procedures. Chemo-prophylaxis and antiretroviral therapy was advised as indicated.

The Flow Counter used in this study was an automated two parameter flow cytometer. In this method, absolute CD4+ cell counts are obtained from a combination of results from flow cytometry and hematoanalysis. Flow cytometry was performed with a FACScan instrument and MultiSET software (Becton Dickinson) modified to accept manual entry of the total white cell count from the $\mathrm{CBC}$ and the percentage of lymphocytes derived from the Attractors software (Becton Dickinson),which reports a three-part differential based on cellsurface makers and side scatters. By use of this dual-plat approach, the MultiSET software reported the absolute CD3+ CD4+ cell counts for the specimen $[3,4]$.

\subsection{Antiretroviral Therapy:}

In the present study, antiretroviral therapy consists of four ART regimens i.e., SLN (Stavudine + Lamivudine + Nevirapine), ZLN (Zidovudine + Lamivudine + Nevirapine), SLE (Stavudine + Lamivudine + Efavirenz) and ZLE (Zidovudine + Lamivudine + Efavirenz).

\subsection{Statistical Analysis:}

Data was collected and analyzed using statistical analysis such as Mean, percentage, standard deviation (SD), standard error of mean(SEM) and paired t-test were performed with MINI TAB 11.12,32 Bit and Microsoft Excel 2007'.

\section{Results}

\subsection{Status of CD4 counts in HIV/AIDS patients taking Antiretroviral Therapy (ART):}

The present chapter gives the status of CD4 counts of 139 study patients under ART at baseline and follow-up at six months. TABLE 1, shows the details of baseline CD4 status according to the age of the study subjects. The age group $21-30$ years has shown low mean CD4 count, so also age groups 31 - 40 years and 41 - 50 years have shown considerably low levels of CD4 counts before initiation of ART. This indicated that, in general population the most vulnerable age for HIV infection is from 21 to 50 years and had shown very low CD4 counts $(<200$ cells $/ \mathrm{cmm})$.

Table 1: Baseline CD4 status according to the age group of the study patients

\begin{tabular}{|l|l|l|l|l|}
\hline $\begin{array}{l}\text { Age group } \\
\text { (years) }\end{array}$ & No. of patients & $\begin{array}{l}\text { Mean } \\
\text { CD4 count } \\
\text { (cells/cmm) }\end{array}$ & Stadard Deviation & Median \\
\hline $1-10$ & 3 & 200.0 & 49.275 & 194.0 \\
\hline $11-20$ & 1 & 100.0 & - & - \\
\hline $21-30$ & 32 & 143.0 & 53.300 & 131.5 \\
\hline $31-40$ & 79 & 159.1 & 44.960 & 160.0 \\
\hline $41-50$ & 24 & 149.7 & 43.010 & 148.0 \\
\hline
\end{tabular}


TABLE 2, presents details of baseline CD4 count of study subjects according to the gender. $45.3 \%$ of male subjects had shown CD4 count of $151-200$ cells/cmm and 51.5\% of females had shown CD4 count of 101 - 150 cells/cmm. This reveals that females shown low CD4 values than males. But together, $43.2 \%$ of the study subjects had shown CD4 count of $101-150$ cells $/ \mathrm{cmm}$ at baseline. There is also a significant change $(\mathrm{t}=2.18, \mathrm{p}$ $<0.05)$ between the baseline CD4 count of male and female subjects. Hence, majority of the patients in our study had shown CD4 count ranging between 101 - 200 cells $/ \mathrm{cmm}$.

Table 2: Baseline CD4 status according to the gender of the study patients

\begin{tabular}{|l|l|l|l|l|l|l|}
\hline $\begin{array}{l}\text { CD4 range } \\
\text { cells/cmm) }\end{array}$ & Male & $\boldsymbol{\%}$ & Female & \% & Total & \% \\
\hline $1-50$ & 2 & 1.9 & 1 & 3.0 & 3 & 2.2 \\
\hline $51-100$ & 3 & 2.8 & 4 & 12.1 & 7 & 5.0 \\
\hline $101-150$ & 43 & 40.6 & 17 & 51.5 & 60 & 43.2 \\
\hline $151-200$ & 48 & 45.3 & 8 & 24.2 & 56 & 40.3 \\
\hline $201-250$ & 7 & 6.6 & 2 & 6.1 & 9 & 6.5 \\
\hline $250-300$ & 2 & 1.9 & 0 & 0 & 2 & \\
\hline $300+$ & 1 & 0.9 & 1 & 3.0 & 2 & 1.4 \\
\hline Total & 106 & 100 & 33 & 100 & 139 & 1.4 \\
\hline
\end{tabular}

$\mathrm{t}=2.18, \mathrm{p}<0.05$

For 139 subjects, the CD4 counts were enumerated for every six months after initiation of ART. A significant increase in CD4 count was observed from baseline to follow-up at six months $(\mathrm{t}=18.84, \mathrm{p}<0.001)$. And pair difference of mean CD4 counts from follow-up to baseline is 171.18 cells/cmm (TABLE 3). Fig. 1, shows the schematic representation of rise in CD4 counts after 6 month follow-up treatment.

Table 3: CD4 status of the patients before and after ART

\begin{tabular}{|c|c|c|c|c|}
\hline S. No. & $\begin{array}{l}\text { CD4 Count (cells/cmm) } \\
\text { at the start of ART } \\
\text { (Baseline) }\end{array}$ & $\begin{array}{l}\text { CD4 count } \\
\text { (cells/cmm) } \\
\text { after } 6 \text { months of ART } \\
\text { (Follow up) }\end{array}$ & $\begin{array}{l}\text { Pair difference } \\
\text { in mean CD4 } \\
\text { (cells/cmm) } \\
\text { (Follow up - } \\
\text { Baseline) }\end{array}$ & $\begin{array}{l}\text { Pair } t \text { - value } \\
\& \\
p \text { - value }\end{array}$ \\
\hline 1. & 126 & 294 & & \\
\hline 2. & 121 & 190 & & \\
\hline 3. & 181 & 383 & & \\
\hline 4. & 131 & 294 & & \\
\hline 5. & 107 & 337 & & \\
\hline 6. & 164 & 396 & & \\
\hline 7. & 137 & 296 & & \\
\hline 8. & 184 & 296 & & \\
\hline 9. & 260 & 300 & & \\
\hline 10. & 142 & 314 & & \\
\hline 11. & 61 & 183 & & \\
\hline 12. & 24 & 221 & & \\
\hline 13. & 168 & 250 & & \\
\hline 14. & 225 & 312 & & \\
\hline 15. & 184 & 270 & & \\
\hline 16. & 196 & 283 & & \\
\hline 17. & 136 & 284 & & \\
\hline 18. & 184 & 360 & & \\
\hline 19. & 150 & 270 & & \\
\hline 20. & 184 & 296 & & \\
\hline 21. & 313 & 290 & 171.18 & $\mathrm{P}<0.001 * *$ \\
\hline 22. & 128 & 296 & & (more significant) \\
\hline 23. & 231 & 335 & & \\
\hline 24. & 167 & 391 & & \\
\hline 25. & 193 & 375 & & \\
\hline 26. & 184 & 296 & & \\
\hline 27. & 69 & 220 & & \\
\hline 28. & 123 & 364 & & \\
\hline 29. & 41 & 254 & & \\
\hline 30. & 128 & 296 & & \\
\hline 31. & 148 & 350 & & \\
\hline 32. & 163 & 275 & & \\
\hline 33. & 252 & 641 & & \\
\hline 34. & 101 & 675 & & \\
\hline 35. & 184 & 294 & & \\
\hline 36. & 128 & 336 & & \\
\hline 37. & 235 & 435 & & \\
\hline
\end{tabular}




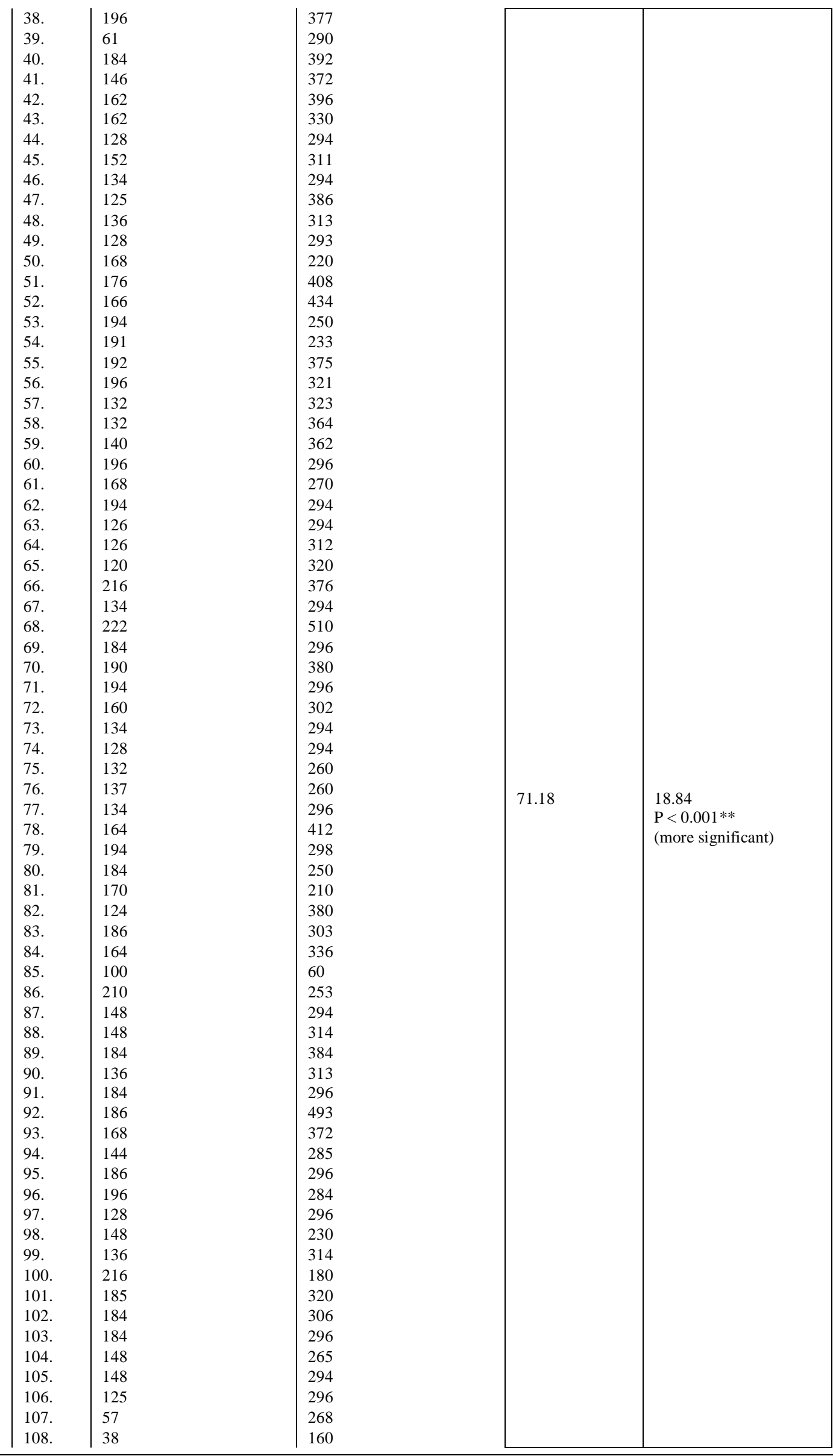




\begin{tabular}{|l|l|l|l|l|}
109. & 160 & 315 & & \\
110. & 199 & 496 & & \\
111. & 110 & 240 & & \\
112. & 126 & 294 & & \\
113. & 157 & 246 & & \\
114. & 110 & 506 & & \\
115. & 123 & 415 & 171.18 & \\
116. & 126 & 294 & & \\
117. & 123 & 394 & & \\
118. & 156 & 846 & $0.001 * *$ \\
119. & 184 & 360 & & \\
120. & 116 & 566 & & \\
121. & 129 & 392 & & \\
122. & 204 & 319 & & \\
123. & 154 & 200 & & \\
124. & 76 & 319 & & \\
125. & 124 & 380 & & \\
126. & 128 & 294 & & \\
127. & 153 & 488 & & \\
128. & 108 & 322 & & \\
129. & 136 & 294 & & \\
130. & 62 & 146 & & \\
131. & 79 & 570 & & \\
132. & 128 & 294 & & \\
133. & 160 & 260 & & \\
134. & 348 & 405 & & \\
135. & 128 & 296 & & \\
136. & 128 & 380 & & \\
137. & 126 & 294 & & \\
138. & 228 & 310 & & \\
139. & 126 & 294 & & \\
\hline
\end{tabular}

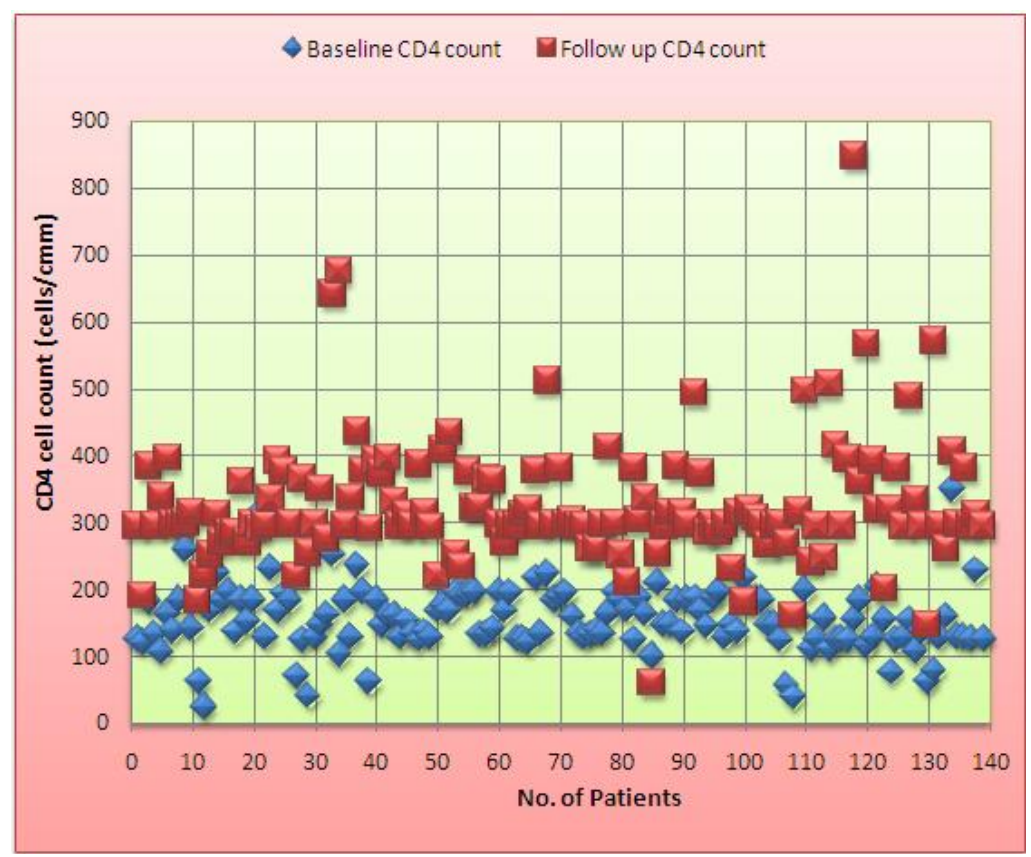

Figure 1: Difference in CD4 counts before and after ART

Fig. 2, shows the distribution of patients according to CD4 counts from 1 to $300+$ cells $/ \mathrm{cmm}$ at Baseline and Follow up treatments. Before initiation of ART all the patients had CD4 counts less than 300 cells/cmm. But after initiation of ART at 6 months follow-up, out of 139 subjects, 67 subjects increased their CD4 counts more than 300 cells/cmm; 57 subjects increased their CD4 counts to $251-300$ cells $/ \mathrm{cmm}$; 9 subjects had shown CD4 count between $201-250$ cells/cmm; 4 subjects shown CD4 count ranging from 151 200 cells/cmm; one subject had shown $101-150$ cells/cmm; another subject had shown $51-100$ cells $/ \mathrm{cmm}$ and no subject had shown CD4 count less than 50 cells $/ \mathrm{cmm}$. There is a drastic change in the CD4 counts of the patients after ART initiation. At baseline, only 2 subjects shown CD4 count $>300$ cells $/ \mathrm{cmm}$ but after 6 months 
of treatment 67 subjects had shown $>300$ cells/cmm. Before ART initiation, 3 subjects had shown CD4 count less than 50 cells/cmm but after 6 months of therapy these subjects increased their CD4 counts, which indicate the positive result. Thus the above results reveals that, majority of the subjects under ART shown rise in CD4 counts during the course of treatment and regular ART to HIV infected subjects prolong their life expectancy.

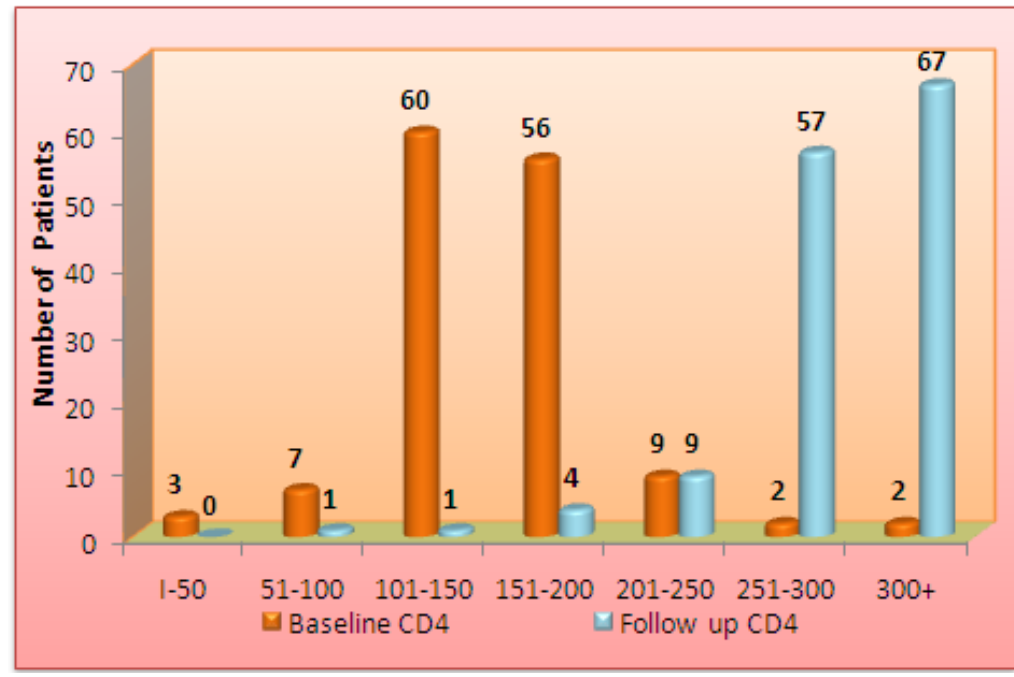

Figure 2: Distribution of HIV patients basing on Baseline and Follow up CD4 cell count

As shown in TABLE 4, the HIV study patients are distributed into WHO clinical stages basing on baseline and follow-up CD4 counts. At baseline, 13(9.4\%) subjects were in Stage-3 who had moderate clinical symptoms, 123(88.5\%) subjects were in Stage-4 with advanced disease, 3(2.2\%) subjects were in Stage-5 with AIDS. But after 6 months of ART therapy, improved levels of CD4 count were observed. At follow-up, 7(5.0\%) subjects were in Stage-2 with mild symptoms, 126(90.7\%) subjects were in Stage-3 with moderate symptoms, only 6(4.3\%) were in Stage-4 and no subjects found in Stage-5 (Fig. 3). Thus ART medication had significant impact on study patients in improving their clinical staging.

Table 4: Distribution of HIV patients according to WHO clinical staging of HIV/AIDS

\begin{tabular}{|l|l|l|l|l|}
\hline \multirow{2}{*}{$\begin{array}{l}\text { Clinical Stage } \\
\text { (basing on CD4 count) }\end{array}$} & \multicolumn{2}{|l|}{$\begin{array}{l}\text { Baseline CD4 Count } \\
\text { of the subjects }\end{array}$} & $\begin{array}{l}\text { Follow up CD4 Count } \\
\text { of the subjects }\end{array}$ \\
\cline { 2 - 5 } & No. & \% & No. & 0 \\
\hline $\begin{array}{l}\text { Stage } 1 \\
>1200 \text { cells/cmm }\end{array}$ & 0 & 0 & 0 & 5.04 \\
\hline $\begin{array}{l}\text { Stage } 2 \\
500-1200 \text { cells/cmm }\end{array}$ & 0 & 0 & 7 & $\mathbf{9 0 . 6 4}$ \\
\hline $\begin{array}{l}\text { Stage } 3 \\
200-500 \text { cells/cmm }\end{array}$ & 13 & 9.35 & 126 & 4.32 \\
\hline $\begin{array}{l}\text { Stage } 4 \\
<200 \text { cells/cmm }\end{array}$ & 123 & $\mathbf{8 8 . 4 9}$ & 6 & 0 \\
\hline $\begin{array}{l}\text { Stage } 5 \\
<50 \text { cells/cmm }\end{array}$ & 3 & 2.16 & 0 & 100 \\
\hline Total & 139 & 100 & 139 & \\
\hline
\end{tabular}

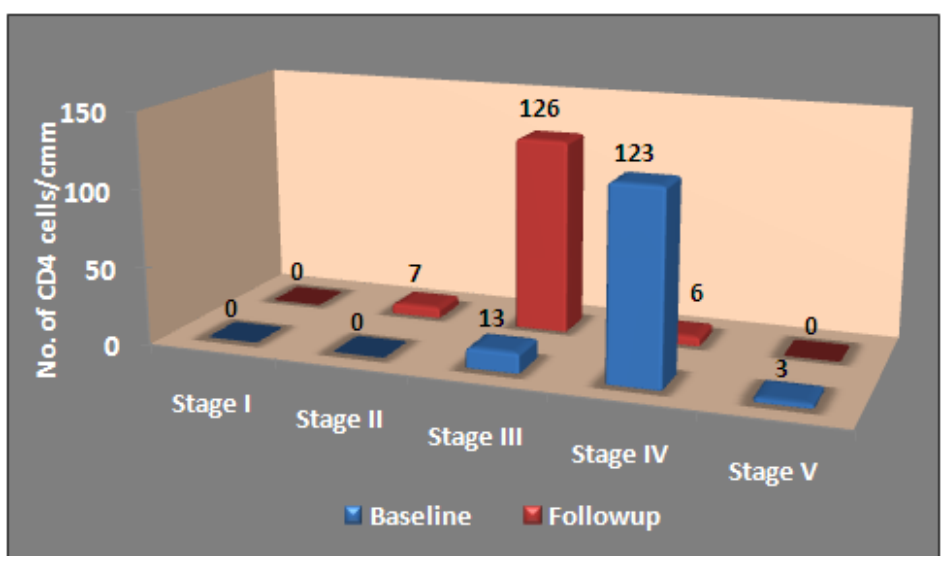


A retrospective study on status of CD4 counts and effect of ART in patients attending VCTC of .....

Figure 3: Distribution of the patients according to the clinical staging of HIV showing improvement after 6 months of ART

\subsection{Effect of Antiretroviral drugs in HIV/AIDS patients under ART:}

In the present study, antiretroviral therapy was started in 139 study patients with four ART regimens i.e., SLN (Stavudine + Lamivudine + Nevirapine), ZLN (Zidovudine + Lamivudine + Nevirapine), SLE (Stavudine + Lamivudine + Efavirenz) and ZLE (Zidovudine + Lamivudine + Efavirenz).

TABLE 5 shows the number of patients taking different ART regimens. $43.9 \%$ of the patients was given ART regimen containing Stavudine (d4T), Lamivudine (3TC), Nevirapine (NVP); $52.5 \%$ was on Zidovudine (ZDV), Lamivudine (3TC), Nevirapine (NVP); $2.2 \%$ was on Stavudine (d4T), Lamivudine (3TC), Efavirenz (EFV) and $1.4 \%$ was on Zidovudine (ZDV), Lamivudine (3TC), Efavirenz (EFV). Thus in the present study, most of the patients were on Nevirapine containing regimen (SLN+ZLN $=96.4 \%$ ). But only $3.6 \%$ of the patients were on Efavirenz containing regimen.

Table 5: ART regimens prescribed for HIV patients

\begin{tabular}{|l|l|l|}
\hline Regimen & $\begin{array}{l}\text { Frequency } \\
\text { (Number of patients) }\end{array}$ & Percentage $(\boldsymbol{\%})$ \\
\hline Stavudine+Lamivudine+Nevirapine & 61 & 43.9 \\
\hline Zidovudine+Lamivudine+Nevirapine & 73 & 52.5 \\
\hline Stavudine+Lamivudine+Efavirenz & 3 & 2.2 \\
\hline Zidovudine+Lamivudine+Efavirenz & 2 & 1.4 \\
\hline Total & 139 & 100 \\
\hline
\end{tabular}

As per TABLE 6, $46.2 \%$ of male subjects and $36.4 \%$ of female subjects were taking SLN regimen with mean age of 34.7 years, $50.9 \%$ of male subjects and $57.6 \%$ of female subjects were on ZLN regimen with mean age 35.1 years, $0.9 \%$ of male subjects and $6.1 \%$ of female subjects were on SLE regimen with mean age 22 years, only $1.9 \%$ of male subjects were on ZLE regimen with mean age 36 years. Hence all the patients under ART are distributed between $22-36$ years which is sexually active age group.

Table 6: Distribution of patients by Age and Gender taking different ART regimens

\begin{tabular}{|l|l|l|l|}
\hline ART Regimen & $\begin{array}{l}\text { Age in Years } \\
(\text { Mean } \pm \text { SD) }\end{array}$ & Male (\%) & Female (\%) \\
\hline SLN $(n=61)$ & $34.7 \pm 6.70$ & $49(46.2)$ & $12(36.4)$ \\
\hline ZLN $(n=73)$ & $35.1 \pm 7.02$ & $54(50.9)$ & $19(57.6)$ \\
\hline SLE $(n=3)$ & $22.0 \pm 12.49$ & $1(0.9)$ & $2(6.1)$ \\
\hline ZLE $(n=2)$ & $36.0 \pm 2.83$ & $2(1.9)$ & $0(0)$ \\
\hline
\end{tabular}

Fig. 4 represents mean CD4 counts of study patients taking different ART regimens. In SLN combination, the baseline mean CD4 count was 148.8 cells $/ \mathrm{cmm}$ and increased to 305.9 cells/cmm (mean) after 6 months follow up. Similarly in ZLN combination, the mean CD4 count increased from 159.7 to 345 cells/cmm; in SLE combination, the mean CD4 count increased from 142.3 to 265 cells/cmm and in ZLE combination, CD4 count increased from 138 to 280 cells $/ \mathrm{cmm}$. 


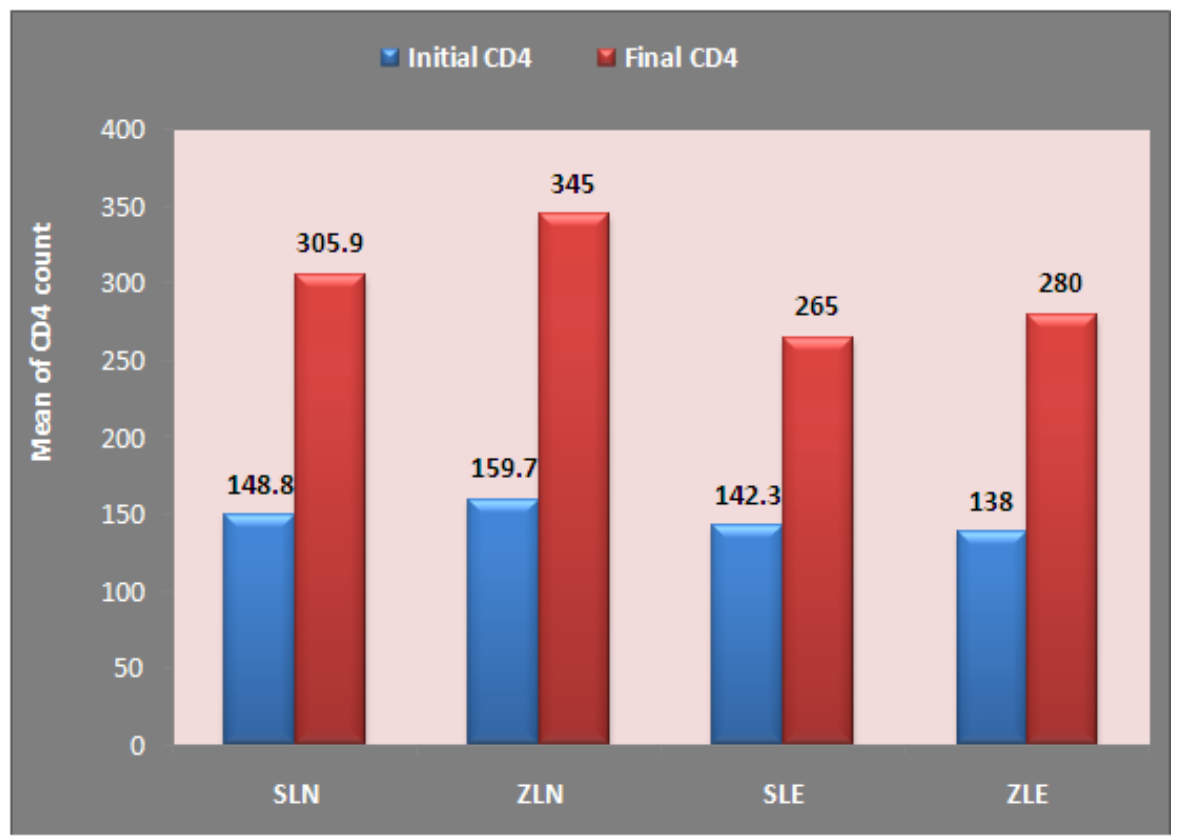

Figure 4: Mean change in CD4 counts with different ARV drug combinations

TABLE 7 shows significant changes in CD4 counts from baseline to follow-up, in study patients taking different ART regimens. Subjects taking SLN $(n=61)$ regimen has shown significant increase with t-value 14.16 and $\mathrm{p}<0.001$; Subjects taking ZLN $(\mathrm{n}=73)$ regimen has shown significant increase with $\mathrm{t}$-value 13.70 and $\mathrm{p}<0.001$; Subjects taking SLE $(\mathrm{n}=3)$ regimen has shown no significant increase with t-value 1.19 and $\mathrm{p}=$ 0.32 ; Subjects taking ZLE $(\mathrm{n}=2)$ regimen has shown no significant increase with t-value 1.14 and $\mathrm{p}=0.46$. Therefore study patients taking Nevirapine containing regimens has shown significant increase in the CD4 levels just after 6 months of follow-up.

Table 7: Effect of Antiretroviral drugs in study patients

\begin{tabular}{|l|l|l|l|l|l|}
\hline $\begin{array}{l}\text { ART } \\
\text { Regimen }\end{array}$ & $\begin{array}{l}\text { Number of } \\
\text { Patients } \\
\text { N(\%) }\end{array}$ & $\begin{array}{l}\text { Baseline CD4 } \\
\text { Count } \\
\text { Mean } \pm \text { SD) }\end{array}$ & $\begin{array}{l}\text { Follow up CD4 } \\
\text { Count } \\
\text { Mean } \pm \text { SD) }\end{array}$ & t-value & p-value \\
\hline SLN & $61(43.9)$ & $148.8 \pm 35.1$ & $305.9 \pm 79.3$ & $14.16^{*}$ & $0.0000^{*}$ \\
\hline ZLN & $73(52.5)$ & $159.7 \pm 52.4$ & $345.0 \pm 103$ & $13.70^{*}$ & $0.0000^{*}$ \\
\hline SLE & $03(2.2)$ & $142.3 \pm 99.0$ & $265.0 \pm 149$ & 1.19 & 0.32 \\
\hline ZLE & $02(1.4)$ & $138.0 \pm 110$ & 1.14 & 0.46 \\
\hline
\end{tabular}

The initial CD4 counts were available for all 139 patients under ART. The mean CD4 count at the time of initiation was 154.2 cells/cmm (median 148, range 24 - 348). After 6 months of treatment the CD4 counts were available for all 139 patients and showed a mean of 325.4 cells/cmm (median 296, range 60 - 846) with a mean rise of 175.7 cells/cmm (TABLE 8$)$. While $136(97.8 \%)$ showed increase in CD4 counts with normal activity after 6 months of ART initiation and 3(2.2\%) patients shown decline in their CD4 counts (TABLE 9). Thus ART in study patients increased the levels of CD4 gradually from baseline to follow-up after 6 months of antiretroviral therapy.

Table 8: Rise in CD4 counts of study patients under ART

\begin{tabular}{|l|l|l|l|l|l|l|l|}
\hline $\begin{array}{l}\text { CD4 } \\
\text { Evaluation }\end{array}$ & $\begin{array}{l}\text { Frequency } \\
\text { (no. } \\
\text { patients) }\end{array}$ & $\begin{array}{l}\text { Mean } \\
\text { CD4 } \\
\text { (cells/ } \\
\text { cmm) }\end{array}$ & $\begin{array}{l}\text { Standard } \\
\text { deviation } \\
\text { (SD) }\end{array}$ & $\begin{array}{l}\text { Standard } \\
\text { error } \\
\text { of Mean } \\
\text { (SEM) }\end{array}$ & $\begin{array}{l}\text { Minimum } \\
\text { (cells/cmm) }\end{array}$ & $\begin{array}{l}\text { Maximum } \\
\text { (cells/cmm) }\end{array}$ & $\begin{array}{l}\text { Median } \\
\text { (cells/ } \\
\text { cmm) }\end{array}$ \\
\hline Baseline & 139 & 154.2 & 47.3 & 4.0 & 24 & 348 & 148.0 \\
\hline 6 months & 139 & 325.4 & 96.1 & 8.1 & 60 & 846 & 296.0 \\
\hline $\begin{array}{l}\text { Rise at } \\
6 \text { months }\end{array}$ & 136 & 175.7 & 95.3 & 8.2 & 40 & 690 & 166.0 \\
\hline
\end{tabular}

Table 9: Performance of the patients under Antiretroviral Therapy

\begin{tabular}{|l|l|}
\hline Feature & Number (\%) \\
\hline Increase in CD4 count after initiation of ART & $136(97.8)$ \\
\hline Decrease in CD4 count & $03(2.2)$ \\
\hline
\end{tabular}


A retrospective study on status of CD4 counts and effect of ART in patients attending VCTC of .....

\begin{tabular}{|l|l|}
\hline No change in CD4 count ( remains stable) & $0(0.0)$ \\
\hline Total & $139(100)$ \\
\hline
\end{tabular}

\section{Discussion}

As per NACO guidelines, currently in India, absolute CD4 cell count is being used as the basis for initiation of ART [5]. In the present study, baseline mean CD4 cell count was $154.2 \pm 47.3$ cells $/ \mu$, which is in agreement with studies conducted [6], the mean CD4 cell count in patients at first visit to Nepal Public Health Laboratory was 155 cells $/ \mathrm{mm}^{3}$, increased to $297 \mathrm{cells} / \mathrm{mm}^{3}$ significantly after six months of ART. The baseline CD4 count is equal with our study but the follow-up count was lower than ours. Peer researchers reported that the gradual CD4 cell count rise are likely to reflect the generation of new cells by peripheral expansion of preexisting T-cell clones or generation of typically derived naive cells among ART patients [7,8].

According to [9], the slope of CD4 cell count increases over 72 weeks in 101 subjects with frequent CD4 cell count and successful virological responses to ART to estimate more precisely the time point soon after ART initiation that best delineates this change in the slope of CD4 cell count measurement. But they found a significant ( $p$ < 0.001) reduction in the slope of the initial CD4 increase, which was apparent at week 8 and 12. Hence, they found that baseline viral load strongly influenced the initial phase of the CD4 cell response to ART is consistent with the suggestion that relatively more lymphocytes, including recent thymic emigrants, are sequestered in lymphoid tissue in persons with higher viral loads, leading to greater CD4 cell redistribution after viral suppression [10].

Similar observations reveal that in their cohort of mainly pretreated patients, an increase of 213 cells $/ \mu \mathrm{l}$ in patients with a baseline CD4 cell count $<200$ cells $/ \mu$ and an increase of only 127 cells $/ \mu 1$ in patients with a baseline CD4 cell count 500-750 cells/ $\mu \mathrm{l}$ [11]. Gracia et al. [12] found in a cohort study from Barcelona that, CD4 cells increased in the whole cohort $(<500$ cells $/ \mu l)$ from a median of 214 cells $/ \mu$ lo 499 cells $/ \mu \mathrm{l}(\mathrm{p}<$ 0.001). According to Patel et al. [13] in 2NN study the nevirapine twice daily and efavirenz group showed median rise 160 cells $/ \mathrm{cmm}$. Tarwater et al. [11] have suggested that the relative immune recovery of patients with lower baseline CD4 cell count is higher than in patients with a high level of baseline CD4+ T cell count.

According to the study of Kunjal Patel et al. [14] lower percentages of CD4+ T-lymphocytes are associated with adverse clinical outcomes among children and adolescents infected with human immunodeficiency virus (HIV). CD4+ lymphocytes percentage generally increases with receipt of highly active antiretroviral therapy (HAART), but long term follow-up is required to assess whether these increases in CD4+ cell percentages are maintained and whether they lead to normal CD4+ cell percentages in children and adolescents with severe immunosuppression. This finding indicated that the treatment was effective. Kunjal Patel et al. [14] reported that, the initial increases in CD4+ cell percentage observed in the first year after HAART initiation are sustained for at least 5 years after HAART initiation among children and adolescents infected with HIV and that greater increases occur among those with the greatest degree of immunosuppression. These findings also suggest that PI-based and NNRTI-based HAART regimens cause similar increases in mean CD4+ cell percentage.

Although age at baseline did not significantly modify these findings, larger improvements in CD4+ cell percentage attributable to HAART initiation were observed among younger children $(<5$ years of age), compared with older children ( $>5$ years of age) which is consistent with previous studies evaluating CD4+ cell response to HAART and may support the hypothesis of greater thymic activity among young children $[15,16$, 17].

The antiretroviral drug Zidovudine was introduced in 1986 for the treatment of HIV/AIDS (NACO). Over the next few years, also other antiretroviral drugs such as nucleoside reverse transcriptase (NRTIs), nonnucleoside reverse transcriptase (NNRTIs) and protease inhibitors (PIs) were introduced and at present, three or more ART drugs are recommended worldwide for the treatment of $\mathrm{HIV}^{+}$[18]. HIV/AIDS patients are rapidly increasing in India with a concentrated epidemic in certain specific population. Keeping in view of this fact free ART was given to eligible persons living with HIV/AIDS as part of National AIDS Control Programme, from April 1, 2004 [19].

In the present study the mean CD4 count in patients at first visit to MGM Hospital was $154.2 \pm 47.3$ cells $/ \mu \mathrm{l}$, increased significantly to $325.4 \pm 96.1 \mathrm{cells} / \mu \mathrm{l}$ after six months of ART $(t=18.84, p<0.001)$. Our finding was in agreement with the result of previous reports $[9,14]$. This finding indicated that the treatment was effective. Similarly, there was immediate response of CD4 count to ART at 6 months of initiation (24 weeks) and significant increase from linear baseline CD4 to linear Follow up CD4 count was observed. Hence, our study confirms the earlier studies.

The present finding co-related with the study of Srirangaraj and Venkatesha [20] that, the first line regimens used in their study were Zidovudine + Lamivudine + Nevirapine (42\%), followed by Stavudine + Lamivudine + Nevirapine (33\%), Stavudine + Lamivudine + Efavirenz (12\%) and Zidovudine + Lamivudine + 
Efavirenz (13\%). So, $75 \%$ of the cases used Nevirapine based regimen. These subjects have adverse effects such as skin rashes (4 cases), anemia ( 2 cases) and peripheral neuropathy ( 2 cases).

In this cohort study, there is significant rise of CD4 count after 6 months of therapy in Nevirapine ( $p<$ 0.0001) administered subjects than in Efavirenz $(p>0.05)$ administered subjects. But according to the report of Patel et al. [13] both NVP and EFV arms had similar rise in CD4 cell count from baseline and at any given point of time there was no difference in the rate of increase of CD4 count between the two treatments $(p=0.58)$. Manfredi et al. [21] in their study found limited immunologic advantage of EFV over NVP to 3 months only, when the mean increases of CD4 cell count Vs. baseline level reached > $40 \%$ for efavirenz and $25 \%$ for nevirapine. But it was not maintained thereafter until 18 months. Single-dose nevirapine is widely used in the developing world to prevent mother- to-child transmission of HIV-1, but it selects for nevirapine- resistant HIV1 in $40 \%-60 \%$ of mothers, as detected by population sequencing within 6-8 weeks of administration [22] and this resistance may compromise subsequent response to nevirapine-containing regimens [23, 24, 25]. Children who are born with infection despite nevirapine prophylaxis have a high risk of developing resistance to nevirpine, which limits their further treatment option [26].

Thus, Use of NVP and EFV based HAART in antiretroviral naive Indian patients led to significant and durable rise in CD4 cell count only after six months of follow up period. In conclusion our observational study showed comparable immunological responses of NVP and EFV based HAART in antiretroviral naive HIV-1 infected patients, with more skin rashes, anaemia, tuberculosis etc. from Warangal district of Andhra Pradesh.

With $>25$ antiretroviral drugs from at least 6 therapeutic classes now available, it is likely that the vast majority of patients who are able to access and adhere to combination therapy will achieve durable viral suppression. The vast majority of patients who have virological response to therapy exhibit sustained increases in their peripheral CD4+ cell count, with most individuals achieving a normal CD4+ cell count [27].

\section{Conclusion}

People with high risk behavior and the spouse of the affected couple need to be educated for primary and secondary prevention of the disease. HIV patients should be educated that the timely initiation and continuous intake of antiretroviral therapy will not only prolong their survival but will also decrease the viral load and transmission of the disease. Provision of free antiretroviral treatment by the government of India is a step in the right direction, and it should be extended to the entire country, as antiretroviral treatment does change the quality of life of the patients as well as his family and the patient is able to get back to work and restart his livelihood. Hence, it can be concluded that ART is effective enough in slowing the progression of HIV infection to AIDS and increasing the survival rate of patients with good performance.

\section{Acknowledgements}

The authors are thankful to Prof. V. Viveka Vardhani, Former Head and Dr. K. Veeraiah, Co-ordinator, Department of Zoology \& Aquaculture, Acharya Nagarjuna University, Andhra Pradesh for providing necessary laboratory facilities. The authors are thankful to APSACS for giving permission to collect the data.

[1]. UNAIDS, World AIDS Day Report, 2011.

\section{References}

[2]. NACO Annual Report, Department of AIDS Control, National AIDS Control Organization, Ministry of Health \& Family Welfare, Government of India, 2010-11, Chapter 1, 1-3.

[3]. A.I. Goldman, B.P. Carlin,L.R. Crane, C. Launer, J.A. Korvick, L. Deyton, and D.I. Abrams, Response of CD4 Lymphocytes and clinical consequences of treatment using ddI or ddC in patients with advanced HIV infection, Journal of Acquired Immune Deficiency Syndromes and Human Retrovirology, 11(2), 1996, 161-169.

[4]. G. Janossy, I. Jani, M. Kahan, D. Barnett, F. Mandy, and H. Shapiro, Precise CD4 T cell counting using red diode laser excitation: for richer, for poorer, Cytometry, 50, 2000, 78-85.

[5]. NCAER, NACO, and UNDP, "Socio-Economic Impact of HIV and AIDS in Andhra Pradesh" This study was conducted by the National Council of Applied Economic Research (NCAER), with support from the National AIDS Control Organisation (NACO) and the United Nations Development Programme (UNDP), 2004-2005.

[6]. B.R. Tiwari, P. Ghimire, and S. Malla, Study on CD4 cell responses in HIV infected subjects in Nepal. Nepal Medical College Journal, 10(1), 2008, 45-47.

[7]. R.M. Gulick, J.W. Mellors, D. Havlir, J.J. Eron, C. Gonzalez, D. McMahon, D.D. Richman, F.T. Valentine, L. Jonas, A. Meibohm, E.A. Emini, J.A. Chodakewitz, P. Deutsch, D. Holder, W.A. Schleif, and J.H. Condra, Treatment with indinavir, zidovudine and lamivudine in adults with human immunodeficiency virus infection and prior antiretroviral therapy. New England Journal of Medicine, 337, 1997, 734-739. doi:10.1056/NEJM199709113371102

[8]. N.G. Pakker, D.W. Notermans, R.J. De Boer, M.T.L. Roos, F. De Wolf, A. Hill, J.M. Leonard, S.A. Danner, F. Miedema, and P.T.A. Schellekens, Biphasic kinetics of peripheral blood T cells after triple combination therapy in HIV-I infection; A composite of redistribution and proliferation. Nature Medicine, 4, 1998, 208-214.

[9]. R.J. Bosch, Rui Wang, F. Vaida, M.M. Lederman, and M.A. Albrecht, Changes in the slope of the CD4 cell count increase after initiation of potent antiretroviral treatment. Journal of Acquired Immune Deficiency Syndrome, 43, 2006, $433-435$. 
[10]. M. Diaz, D.C. Douek, H. Valdez, B.J. Hill, D. Peterson, I. Sanne, P.J. Piliero, R.A. Koup, S.B. Green, S. Schnittman, and M.M. Lederman, T cells containing $\mathrm{T}$ cell receptor excision circles are inversely related to HIV replication and are selectively and rapidly released into circulation with antiretroviral treatment, AIDS, 17(8), 2003, 1145-1149.

[11]. P.M. Tarwater, J.B. Margolick, J. Jin, J.P. Phair, R. Detels, C. Rinaldo, J. Giorgi, and A. Muñoz, Increase and plateau and CD4 Tcell counts in the 3(1/2) years after initiation of potent antiretroviral therapy. Journal of Acquired Immune Deficiency Syndromes, $27,2001,168-175$.

[12]. F. Gracia, E. de Lazzari, M. Plana, P. Castro, G. Mestre, M. Nomdedeu, E. Fumero, E. Martinez, J. Mallolas, J.L. Blanco, J.M. Miro, T. Pumarola, T. Gallart, and J.M. Gatell, Long- term CD4+ T-cell response to highly active antiretroviral therapy according to baseline CD4+ T-cell count. Journal Acquired Immune Deficiency Syndrome, 36, 2004, 702-713.

[13]. A.K. Patel, S. Pujari, K. Patel, J. Patel, N. Shah, B. Patel, and N. Gupta, Nevirapine versus Efavirenz based antiretroviral treatment in naïve Indian patients: comparison of effectiveness in clinical cohort. Journal of the Association of Physicians of India, (54), 2006, 915-918.

[14]. Kunjal Patel, Miguel A. Hernán, Paige L. Williams, John D. Seeger, Kenneth McIntosh, Russell B. Van Dyke, George R. Seage III, and Pediatric AIDS Clinical Trials Group 219/219C Study Team, Long-term effects of Highly Active Antiretroviral Therapy on $\mathrm{CD}^{+}$cell evolution among children and adolescents infected with HIV: 5 Years and Counting. Clinical Infectious Diseases, 46(11), 2008, 1751-1760.

[15]. C.H. Soh, J.M. Oleske, and M.T. Brady, Long term effects of protease inhibitor-based combination therapy on CD4 T-cell recovery in HIV-1 infected children and adolescents. Lancet, 362, 2003, 2045-2051.

[16]. S.M. Essajee, M. Kim, C. Gonazalez, M. Rigaud, A. Kaul, S. Chandwani, W. Hoover, R. Lawrence, H. Spiegel, H. Pollack, K. Krasinki, and W. Borkowsky, Immunologic and virologic response to HAART in severely immunocompromised HIV-1 infected children. AIDS, 13, 1999, 2523-2532.

[17]. A.S. Walker, K. Doerholt, M. Sharland, and D.M. Gibb, Response to highly active antiretroviral therapy varies with age: the UK and Ireland Collaborative HIV Pediatric Study. AIDS, 18(14), 2004, 1915-1924.

[18]. CDC, Guidelines for using antiretroviral agents among HIV infected adults and adolescents. Morbidity and Mortality Weekly Report, 51, 2006, 7.

[19]. NACO, Guidelines on HIV care and treatment in infants and children, Ministry of Health and Family Welfare; Management of Opportunistic Infections in children, B, 2006, 53-74.

[20]. S. Srirangaraj, and D. Venkatesha, Adverse effects after HAART initiation in resource-limited settings: a prospective study from Mysore, India. Journal of Infection in Developing Countries, 4(11), 2010, 750-753.

[21]. R. Manfredi, L. Calza, F. Cheiodo, M. Leonardo, and M.D. Francesco, Efavirenz versus Nevirapine in current clinical practice: A prospective open-label observational study. Journal of Acquired Deficiency Syndrome, 35, 2004, 492-502.

[22]. S. Lockman, and J.A. McIntyre, Reduction of HIV -1 drug resistance after intrapartum single dose nevirapine. Lancet 370, 2007, 1668-1670.

[23]. T. Toni, B. Masquelier, A. Minga, X. Analart, C. Danel, A. Coulibaly, H. Chenal, F. Dabis, R. Salamon, and H. Fleury, HIV-1 antiretroviral drug resistance in recently infected patients in Abidjan, Cote d'Ivoire: a 4-year survey, 2002-2006. AIDS Research Human Retroviruses, 23, 2007, 1155-1160. doi:10.1089/aid.2007.0072

[24]. WHO, WHO consultation on technical and operational recommendations for scale-up of laboratory services and monitoring HIV antiretroviral therapy in resource-limited settings, 2007.

[25]. P.A. Coffie, D.K. Ekouevi, M.L. Chaix, B.T. Gold, A.B. Clarisse, R. Becquet, I. Viho, T.D. Yoman, V.R. Leroy, E.J. Abrams, C. Rouzioux, and F.O. Dabis, Maternal 12-month response to antiretroviral therapy following prevention of mother -to-child transmission HIV type 1, Ivory Coast, 2003-2006. Clinical Infectious diseases, 46, 2008, 611-621.

[26]. S. Lockman, R.L. Shapiro, L.M. Smeaton, C. Wester, I. Thior, L. Stevens, F. Chand, J. Makhema, C. Moffat, A. Asmelash, P. Ndase, P. Arimi, E.V. Widenfelt, L. Mazhani, V. Novitsky, S. Lagakos, and M. Essex, Response to antiretroviral therapy after a single, peripartum dose of nevirapine. New England Journal of Medicine, 356, 2007, 135-147.

[27]. L. Gras, A.M. Kesselring, J.T. Griffin, A.I. Van Sighem, C. Fraser, A.C. Ghani, F. Miedema, P. Reiss, J. Lange, and F. de Wolf, CD4 cell counts of 800 cells $/ \mathrm{mm}^{3}$ or greater after 7 years of highly active antiretroviral therapy are feasible in most patients starting with 350 cells $/ \mathrm{mm}^{3}$ or greater. Journal of Acquired Immune Deficiency Syndrome, 45(2), 2007, 183-192. 